\title{
Phenolic Content, Flavonoid Content and Antioxidant Potential of Whole Plant Extract of Ophiorrhiza pectinata Arn.
}

\author{
S. N. PREETHAMOL ${ }^{* 1}$ AND J. E. THOPPIL ${ }^{*}$
}

${ }^{1}$ Research scholar, Cell and Molecular Biology Division, Department of Botany, University of Calicut, Kerala, India, 673635, 2Professor, Cell and Molecular Biology Division, Department of Botany, University of Calicut, Kerala, India, 673635

Preethamol et al.: Phenolic and flavonoid content and antioxidant potential of Ophiorrhiza pectinata

The present study was designed to evaluate the antioxidant potential of the methanolic extract of Ophiorrhiza pectinata using various in vitro methods and the quantitative estimation of phenols and flavonoids in the extract. The total phenolic content of the extract was estimated using Folin-ciocalteu assay and the result was obtained as $41.59 \pm 0.51 \mathrm{mg}$ gallic acid equivalent per gram dry weight (GAE $/ \mathrm{g} \mathrm{DW}$ ) of the extract. Estimation of the flavonoid content was done by aluminium chloride calorimetric method and the result was $21.01 \pm 0.73 \mathrm{mg}$ quercetin equivalent per gram dry weight $(\mathrm{QE} / \mathrm{g} \mathrm{DW})$ of the extract. Antioxidant potential of the extract was screened against free radicals like 1,1-diphenyl-2-picryl hydrazyl (DPPH), hydroxyl, nitric oxide and superoxide. The results of the assays were calculated as the percentage inhibition of these radicals by the extract. In DPPH radical scavenging assay the percentage inhibition was obtained as $\mathbf{6 4 . 0 6} \pm \mathbf{1 . 1 2} \%$, in hydroxyl radical scavenging assay the percentage inhibition was $66.67 \pm 1.005 \%$, in nitric oxide radical scavenging assay the percentage inhibition was $67.37 \pm 1.006 \%$ and in superoxide radical scavenging assay the result was obtained as $74.29 \pm 1.06 \%$. In all the scavenging assays, the extract showed a dose dependent increase in free radical scavenging activity. The percentage inhibition of the radicals also increased with increasing concentration of the plant extract. The results suggested that the antioxidant efficacy of the plant extract might be due to the presence of phenol and flavonoid compounds that are known for their antioxidant properties. The study also justifies the use of the plant in folklore medicine for the treatment of various ailments. In conclusion, the plant extract can be a potent source of natural antioxidant that can be explored for research and therapeutic applications.

Key words: Ophiorrhiza pectinata, Phenol, Flavonoid, Antioxidant, Bioactivity, Therapeutic 
As per the reports of World Health Organisation, majority of the world's population depends on plants or plant based products for health care needs as plants are rich source of effective and safe medicines ${ }^{[1]}$. The medicinal properties of the plants are due to the presence of bioactive secondary metabolites like phenols, flavonoids, tannins, alkaloids, terpenoids and saponins. These compounds are produced by plants as a result of various physiological processes ${ }^{[2]}$. The synergistic effects of these metabolites attribute various pharmacological activities. Hence, they play a great role in preventing several diseases like cancer, neurodegenerative diseases and cardiovascular problems by different biological mechanisms ${ }^{[3]}$.

Antioxidant property is an important bioactivity of medicinal plants that has gained the attention of several research studies. Metabolic reactions within the living organisms produce highly unstable reactive oxygen species (ROS) that attack other stable molecules. To attain stability they capture electrons from stable molecules and initiate a chain of reactions ${ }^{[4]}$. ROS includes oxygen-derived free radicals like superoxide, nitric oxide, hydroxyl radical as well as non-radical oxygen derivatives like hydrogen peroxide, singlet oxygen, peroxynitrite and hypochlorite ${ }^{[5]}$. They may react with protein molecules, DNA molecules, lipids, cells of brain and immune system and cause oxidative stress. Enhanced level of ROS can lead to premature ageing, heart diseases, chronic inflammation, arthritis, asthma, diabetes and stroke ${ }^{[6]}$. Antioxidants are substances that slow down or inhibit the oxidation of biological molecules by free radicals and thereby prevent cell damage ${ }^{[7]}$. Living organisms have an endogenous system of antioxidants, in the form of enzymatic and non-enzymatic antioxidants, for repairing the cell damage caused by free radicals. But ROS are highly unstable and cause rapid oxidative reactions leading to cell death bypassing the effects of endogenous antioxidants. Thus there is a growing need for exogenous antioxidants from natural sources ${ }^{[8]}$ as medicines from plants are generally considered safer than synthetic ones ${ }^{[9]}$. Antioxidant properties of plants are considered to be the contribution of phenolic and flavonoid compounds that may be present in almost all the parts of a plant ${ }^{[10]}$. Thus medicinal plants with phenol and flavonoid contents are investigated for their antioxidant properties ${ }^{[1]}$. The present study was designed to assess the antioxidant potential, total phenol

*Address for correspondence

E-mail: preethamolsn92@gmail.com

713 and total flavonoid content of the methanolic extract of the plant, Ophiorrhiza pectinata Arn., belonging to the family Rubiaceae. Ophiorrhiza L. is a species-rich genus with 321 species, 5 varieties and 1 subspecies ${ }^{[12]}$. The plants are distributed in the wet tropical forests of South-East Asia, extending to Australia, New Guinea and Pacific Islands. These small, herbaceous or shrubby plants have many medicinal properties and have been used in folklore medicine for the treatment of various ailments like ulcers, leprosy, gastropathy and amenorrhea ${ }^{[13]}$. Earlier studies on the aqueous leaf extract of the plant have reported antibacterial activities and antioxidant ability against a single free radical $\mathrm{DPPH}^{[14]}$. Literature survey on phytochemical screening suggests that though extraction process can be done using several solvents, the maximum number of secondary metabolites gets dissolved in methano ${ }^{[15-17]}$. Thus the potential of methanolic whole plant extract to scavenge different types of free radicals and the quantitative estimation of the phenol and flavonoid content present in the extract is done for the first time in this study. Fresh plant materials (whole plant) of $O$. pectinata were collected from Idukki district of Kerala, India. The collected plant materials were authenticated by Prof. M. Sabu, Department of Botany, University of Calicut, Kerala. The voucher specimen (CALI no: 143972) was deposited in the Calicut University herbarium. The collected plants were thoroughly washed and were shade dried at the room temperature. After drying, they were chopped and powdered in a blender and the plant powder was stored in moist free sealed container. For the preparation of the plant extract, $20 \mathrm{~g}$ of the plant powder was extracted with $200 \mathrm{ml}$ of $100 \%$ methanol using Soxhlet extractor for $6 \mathrm{~h}$ at $50-60^{\circ}$. The methanolic extract thus obtained was allowed to cool, then filtered through Whatman filter paper No.1 and the filtrate was concentrated at $60^{\circ}$. The final extract was then stored in dark at $4^{\circ}$ for further experiments. The total phenolic content of the extract was determined by the Folin - ciocalteu assay $^{[18]}$. In brief, $0.1 \mathrm{ml}$ of the extract $(1 \mathrm{mg} / \mathrm{ml})$ was mixed with $0.5 \mathrm{ml}$ of distilled water and $0.125 \mathrm{ml}$ This is an open access article distributed under the terms of the Creative
Commons Attribution-NonCommercial-ShareAlike 3.0 License, which
allows others to remix, tweak, and build upon the work non-commercially,
as long as the author is credited and the new creations are licensed under
the identical terms

Accepted 28 July 2020

Revised 22 May 2020

Received 27 December 2019 Indian J Pharm Sci 2020;82(4):712-718 
of Folin - ciocalteu reagent $(1 \mathrm{~N})$ and shaken well. After incubation for $5 \mathrm{~min}, 1.25 \mathrm{ml}$ of $7 \%$ of sodium carbonate $(\mathrm{w} / \mathrm{v})$ was added and the final volume of the solution was made up to $3 \mathrm{ml}$ with distilled water. The reaction mixture was shaken well and incubated in dark for $90 \mathrm{~min}$ and the absorbance was measured against a blank at $760 \mathrm{~nm}$. Gallic acid was used as the standard. The TP content of the methanolic extract was calculated from the calibration curve of gallic acid and the results were expressed in milligram of gallic acid equivalent per gram dry weight (mg GAE/g DW) using regression equation. The samples were analyzed in triplicates. The total flavonoid content of the extract was determined using aluminium chloride $\left(\mathrm{AlCl}_{3}\right)$ calorimetric method ${ }^{[18]}$, with slight modifications. Briefly, $0.5 \mathrm{ml}$ of the extract $(1 \mathrm{mg} / \mathrm{ml})$ was mixed with $0.5 \mathrm{ml}$ of distilled water and $0.3 \mathrm{ml}$ of $5 \%$ sodium nitrate $(\mathrm{w} / \mathrm{v})$ and incubated for $5 \mathrm{~min}$ at $25^{\circ}$. Incubation was followed by the immediate addition of $0.3 \mathrm{ml}$ of $10 \% \mathrm{AlCl}_{3}(\mathrm{w} / \mathrm{v})$. The reaction mixture was shaken well and $2 \mathrm{ml}$ of $1 \mathrm{M}$ sodium hydroxide was added. The absorbance of the solution was measured against a blank at $510 \mathrm{~nm}$. Quercetin was used as the standard. The TF content of the methanolic extract was calculated from the calibration curve of quercetin using regression equation and the results were expressed in milligram of quercetin equivalent per gram dry weight $(\mathrm{mg} \mathrm{QE} / \mathrm{g}$ DW). The samples were analyzed in triplicates. The ability of the plant extract to scavenge 1,1-Diphenyl2-picryl-hydrazyl (DPPH) free radicals was determined using the method of Chang et al. ${ }^{[19]}$. $0.1 \mathrm{mM} \mathrm{DPPH}$ solution was prepared by dissolving $4 \mathrm{mg}$ of DPPH in $100 \mathrm{ml}$ of methanol. Different concentrations of sample (12.5. 25, 50, 100, $200 \mu \mathrm{g} / \mathrm{ml})$ from stock solution were made up to a final volume of $20 \mu 1$ with dimethyl sulphoxide (DMSO) and $1.48 \mathrm{ml}$ DPPH $(0.1 \mathrm{mM})$ solution was added. The reaction mixture was then incubated in dark at room temperature for $20 \mathrm{~min}$. After incubation, the absorbance of the mixture was read against a blank at $517 \mathrm{~nm}$. A control without the test compound, but an equivalent amount of distilled water was taken. Ascorbic acid was used as the standard. The ability to scavenge the DPPH radical was expressed as percentage inhibition and calculated using the eqn Percentage inhibition $=A_{c}-A_{s} / A_{c} \times 100$, where, $A c$ is the absorbance of the control; As is the absorbance of the sample. All the samples were tested in triplicates.

The potential of the plant extract to scavenge hydroxyl radicals generated by the Fenton reaction was determined using the method of Kunchandy and $\mathrm{Rao}^{[20]}$. Aliquots $(12.5 \mu \mathrm{l}-200 \mu \mathrm{l})$ of different concentrations of the sample were taken from a stock concentration $(10 \mathrm{mg} / \mathrm{ml} \mathrm{DMSO})$ and were mixed with $500 \mu \mathrm{l}$ of reaction mixture to a final volume of $1 \mathrm{ml}$. The reaction mixture contained deoxyribose $(2.8 \mathrm{mM})$, ferric chloride $(0.1 \mathrm{mM})$, ethylenediaminetetraacetic acid (EDTA) $(0.1 \mathrm{mM})$, hydrogen peroxide $(1 \mathrm{mM})$, ascorbate $(0.1 \mathrm{mM})$ and phosphate buffer $(20 \mathrm{mM}$, $\mathrm{pH}$ 7.4). After incubation for $1 \mathrm{~h}$ at $37^{\circ}, 1 \mathrm{ml}$ of $2.8 \%$ trichloroacetic acid (TCA) was added. Then, $1 \mathrm{ml}$ of $1 \%$ aqueous thiobarbituric acid (TBA) was added and the solution was incubated at $90^{\circ}$ for $15 \mathrm{~min}$. After cooling, the absorbance of the solution was measured at $532 \mathrm{~nm}$ against a suitable blank. A control without the test compound, but an equivalent amount of distilled water was taken. Gallic acid was used as the standard. The ability to scavenge hydroxyl radical was expressed as percentage inhibition and calculated using the equation Percentage inhibition $=\mathrm{A}_{\mathrm{c}}-\mathrm{A}_{\mathrm{s}} / \mathrm{A}_{\mathrm{c}} \times 100$, where, Ac is the absorbance of the control; As is the absorbance of the sample. All the samples were tested in triplicates.

Sodium nitroprusside in aqueous solution at physiological $\mathrm{pH}$ spontaneously generates nitric oxide that interacts with oxygen to produce nitrite ions that can be estimated using Griess reagent. The ability of the plant extract to scavenge nitric oxide radicals was determined following the methodology of Kumaran and Karunakaran ${ }^{[21]}$, with sight modifications. Sodium nitroprusside $(5 \mathrm{mmol} / \mathrm{l})$ in phosphate buffer saline (PBS) of $\mathrm{pH} 7.4$ was mixed with different concentration of sample $(125,250,500,1000,2000 \mu \mathrm{g} / \mathrm{ml})$ taken from a stock concentration of $10 \mathrm{mg} / \mathrm{ml}$ DMSO. The solution was incubated at $25^{\circ}$ for $30 \mathrm{~min}$. After incubation, $1.5 \mathrm{ml}$ of the incubated solution was removed and diluted with $1.5 \mathrm{ml}$ of Griess reagent (1\% sulphanilamide, $2 \%$ phosphoric acid and $0.1 \%$ N-1-naphthyl ethylene diaminedihydrochloride). Absorbance of the chromophore formed during diazotization of the nitrate with sulphanilamide and subsequent coupling with N-1 naphathyl ethylene diaminedihydrochloride was measured against the blank at $546 \mathrm{~nm}$. A control without the test compound, but an equivalent amount of distilled water was taken. Gallic acid was used as the standard. The ability to scavenge nitric oxide radical was expressed as percentage inhibition and calculated using the equation. Percentage inhibition $=\mathrm{A}_{\mathrm{c}}-\mathrm{A}_{\mathrm{s}} /$ $\mathrm{A}_{\mathrm{c}} \times 100$ where, Ac is the absorbance of the control; As is the absorbance of the sample. All the samples were tested in triplicates. Superoxide anions are generated in riboflavin-nicotinamide adenine dinucleotide (NADH) system by the oxidation of NADH. The ability of the plant extract to scavenge the radicals is assayed by 
the reduction of nitroblue tetrazolium (NBT) by the generated super oxide anions, resulting in the formation of blue formazan product, following the methodology of Valentao et al. ${ }^{[22]}$. Different concentrations of sample $(125,250,500,1000,2000 \mu \mathrm{g} / \mathrm{ml})$ were taken from a stock solution of $10 \mathrm{mg} / \mathrm{ml}$ and mixed with $0.05 \mathrm{ml}$ of riboflavin solution $(0.12 \mathrm{mM}), 0.2 \mathrm{ml}$ of EDTA solution $(0.1 \mathrm{M})$ and $0.1 \mathrm{ml} \mathrm{NBT}$ solution $(1.5 \mathrm{mM})$. The reaction mixture was diluted up to $2.64 \mathrm{ml}$ with phosphate buffer $(0.067 \mathrm{M})$. The solution was illuminated with fluorescent light for $5 \mathrm{~min}$ and the absorbance was measured at $560 \mathrm{~nm}$. The solution was again illuminated for $30 \mathrm{~min}$ and absorbance was measured at $560 \mathrm{~nm}$ using UV visible spectrophotometer. Difference in the optical density(OD) was calculated. A control without the test compound, but an equivalent amount of distilled water was taken; Ascorbic acid was used as the standard. The ability to scavenge super oxide radical was expressed as percentage inhibition and calculated using the eqn Percentage inhibition $=\mathrm{A}_{\mathrm{c}}-\mathrm{A}_{\mathrm{s}} / \mathrm{A}_{\mathrm{c}} \times 100$ where, $\mathrm{Ac}$ is the absorbance of the control; As is the absorbance of the sample. All the samples were tested in triplicates.

All the statistical analyses were done using the SPSS Version 20 software programme. The data obtained were subjected to one way Analysis of Variance (ANOVA) and Duncan's multiple range tests to validate the results. The results were expressed as mean \pm standard error (SE), and those with $\mathrm{p}<0.05$ were treated as statistically significant. The half maximal inhibitory concentration $\left(\mathrm{IC}_{50}\right)$ or the sample concentration providing 50\% inhibition was calculated using ED50 PLUS V1.0 Software. The TP content of the methanolic extract of $O$. pectinata was calculated from the calibration curve of gallic acid and the result was observed as $41.59 \pm 0.51 \mathrm{mg} \mathrm{GAE} / \mathrm{g}$ DW. Also, the TF content of the plant extract was calculated from the calibration curve of quercetin and was found to be $21.01 \pm 0.73 \mathrm{mg} \mathrm{QE} / \mathrm{g}$ DW. The plant extract exhibited a dose-dependent increase in its free radical scavenging potential in all the four assays. The inhibition percentage of the radicals also increased with increasing concentration of the extract in all the antioxidant experiments. The concentrations used for the assay were $12.5,25,50,100$ and $200 \mu \mathrm{g} / \mathrm{ml}$ of the plant extract. The maximum scavenging effect of the plant extract at the highest concentration of $200 \mu \mathrm{g} / \mathrm{ml}$ was observed as $64.06 \pm 1.12 \%$. Ascorbic acid was used as the standard which showed inhibition of $96.15 \pm 0.67 \%$ at the highest concentration. $\mathrm{IC}_{50}$ value of the crude extract was found to be $123.434 \mu \mathrm{g} / \mathrm{ml}$, whereas, for ascorbic acid, the value was $38.4205 \mu \mathrm{g} / \mathrm{ml}$. As the $\mathrm{IC}_{50}$ value of the plant extract was within the range of selected concentrations; it can be inferred that methanolic extract of $O$. pectinata have significant scavenging effects on the DPPH radical. The ability of the plant extract to scavenge hydroxyl radicals was tested using different concentrations of the plant extract i.e., 125, 250, 500, 1000 and $2000 \mu \mathrm{g} / \mathrm{ml}$. Maximum scavenging ability of the crude extract was found to be $66.67 \pm 1.005 \%$ and that of gallic acid was $90.96 \pm$ $0.63 \%$. The $\mathrm{IC}_{50}$ value of the plant extract was observed to be $842.262 \mu \mathrm{g} / \mathrm{ml}$ and that of the standard was $477.491 \mu \mathrm{g} / \mathrm{ml}$. The $\mathrm{IC}_{50}$ value of the plant extract was within the range of selected concentrations and thus the plant extract has significant hydroxyl radical scavenging potential. In nitric oxide radical scavenging assay, the concentrations tested were 125, 250, 500, 1000 and $2000 \mu \mathrm{g} / \mathrm{ml}$ of the plant extract. Maximum scavenging ability of the crude extract was found to be $67.37 \pm$ $1.006 \%$ at the highest concentration and that of gallic acid was $92.90 \pm 1.04 \%$. Thus the plant extract has considerable nitric oxide radical scavenging ability with an $\mathrm{IC}_{50}$ value of $879.237 \mu \mathrm{g} / \mathrm{ml} \mathrm{IC}_{50}$ value of the standard was $108.809 \mu \mathrm{g} / \mathrm{ml}$. Here also, $\mathrm{IC}_{50}$ value of the plant extract was within the range of selected concentrations. Concentrations of the plant extract tested for the assay were 125, 250, 500, 1000 and $2000 \mu \mathrm{g} / \mathrm{ml}$. Maximum scavenging ability of the crude extract was found to be $74.29 \pm 1.06 \%$ and that of ascorbic acid was $90.68 \pm 1.11 \%$. The $\mathrm{IC}_{50}$ value of the plant extract was observed to be $737.483 \mu \mathrm{g} / \mathrm{ml}$ and that of the standard was $238.357 \mu \mathrm{g} / \mathrm{ml}$. As the $\mathrm{IC}_{50}$ value of the plant extract was within the range of selected concentrations the plant extract has notable superoxide radical scavenging potential. Phenols donate hydrogen atoms from their hydroxyl groups to the free radicals and form stable phenoxy radicals ${ }^{[23]}$. Flavonoids are polyphenols with two or more phenol subunits ${ }^{[24]}$. Both these compounds neutralize oxidizing radicals like superoxide and hydroxyl radical by the property of metal chelation ${ }^{[7]}$. Thus antioxidant properties of phenolic compounds are mainly due to their potential to behave as reducing agents, radical scavengers and metal chelators and their chain breaking actions ${ }^{[10]}$. In the present study, the methanolic plant extract showed significant level of phenol and flavonoid content and can probably support the antioxidant potential of the plant. As in vitro assays are largely dependent on the chemical and physical parameters of the system in which the reaction takes place, a single protocol may not give valid result ${ }^{[11]}$. So four different antioxidant assays were used to evaluate the antioxidant potential. 
DPPH radical scavenging assay is a fast experiment and has direct relation with the phenolic content. So it is one of the most commonly used experiments to determine the antioxidant potential of the plant extracts $^{[25]}$. The method is based on the scavenging of the DPPH radical by the antioxidants present in the sample that decolourises the deep purple DPPH by reduction reaction. The greater discolouration occurs, the lower absorbance is found indicating significant free radical scavenging capacity ${ }^{[26]}$. In the present study, the methanolic extract of the plant exhibited significant scavenging effects on the DPPH radical. Fig. 1 shows the increasing percentage inhibition of the radical by the plant extract with increasing concentration. This suggests that the plant extract has a dose dependent effect on the DPPH radicals. Hydroxyl radicals are the most potent reactive oxygen species that can interact with all the biological molecules. They cause lipid peroxidation, protein damage and membrane disruption. Hydroxyl radicals are very dangerous as the cells have no enzymatic mechanism for their removal[ ${ }^{[27]}$. They can attack DNA and form protein crosslinks that cannot be easily repaired, hence causing cell death ${ }^{[28]}$. Hydroxyl radical scavenging activity is determined by measuring the inhibition of degradation of 2-deoxyribose by the radicals generated by Fenton reaction. The radicals degrade 2-deoxy-2-ribose into fragments that upon heating with TBA at low $\mathrm{pH}$ form a red colour ${ }^{[24]}$. So the antioxidant activity is measured by the low intensity of the red colour. Fig. 2 shows the increasing inhibition percentage of hydroxyl radicals by the plant extract indicating significant hydroxyl radical scavenging activity. In nitric oxide radical scavenging assay, nitric oxide is produced when sodium nitroprusside decomposes in aqueous solution. These radicals then react with oxygen to produce nitrates and nitrites, which can be estimated using Griess reagent ${ }^{[29]}$. Thus the antioxidants, compete with oxygen resulting in reduced nitrite ion production ${ }^{[24]}$. Fig. 3 illustrates the percentage inhibition of nitric oxide by the methanolic plant extract. A dose dependent increase in percentage inhibition of the radicals can be observed. Superoxides are the primary ROS formed in the cell ${ }^{[30]}$. Though they are weak oxidants, they can produce secondary ROS like the dangerous hydroxyl radicals and singlet oxygen species which cause oxidative stress ${ }^{[31]}$. Fig. 4 shows the dose dependent scavenging activity of the plant extract on superoxide radicals that indicate the inhibition capacity of the methanolic extract of the plant. While comparing the $\mathrm{IC}_{50}$ values obtained for the plant extract with that of the standards in different assays, the study

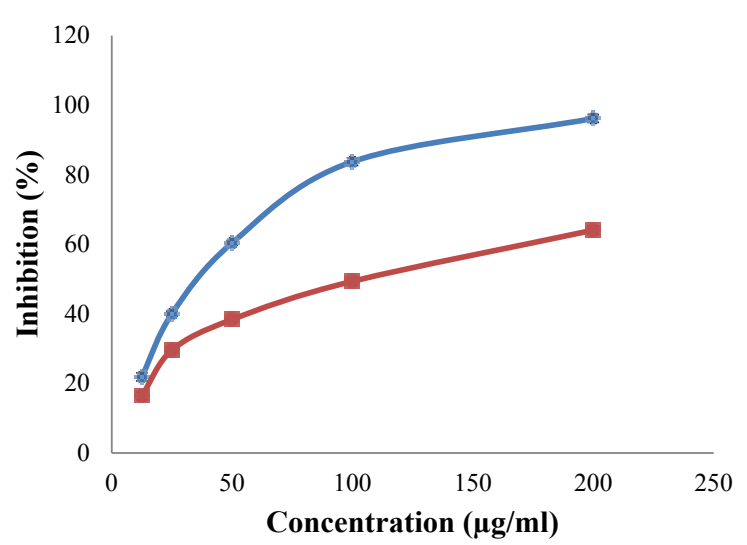

Fig. 1: Percentage inhibition curves in the DPPH free radical scavenging assay

$(-\downarrow-)$ ascorbic acid; (-匹-) methanolic extract of Ophiorrhiza pectinata

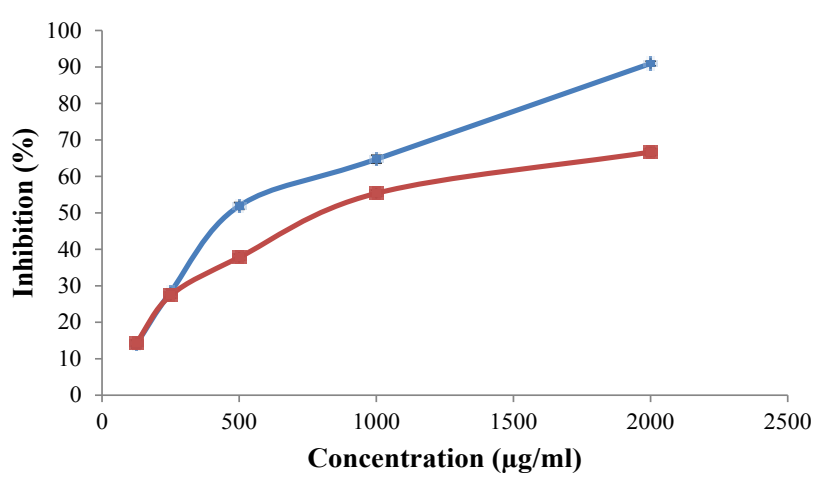

Fig. 2: Percentage inhibition curves in the hydroxyl radical scavenging assay

$(-\downarrow)$ gallic acid; (- -$)$ methanolic extract of Ophiorrhiza pectinata

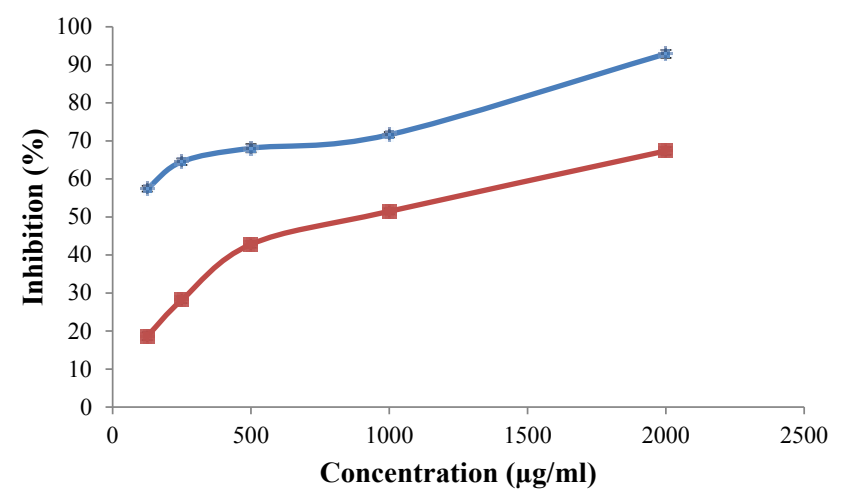

Fig. 3: Percentage inhibition curves in the nitric oxide radical scavenging assay

$(-\downarrow)$ gallic acid; (- - ) methanolic extract of Ophiorrhiza pectinata

suggest that the plant extract can be a useful antioxidant agent. In all the assays, the standards used are pure compounds that can exhibit the maximum free radical scavenging activity, whereas the samples analysed are plant extracts with numerous compounds and metabolites. Thus the scavenging activity showed by the samples might be due to the antioxidant properties 


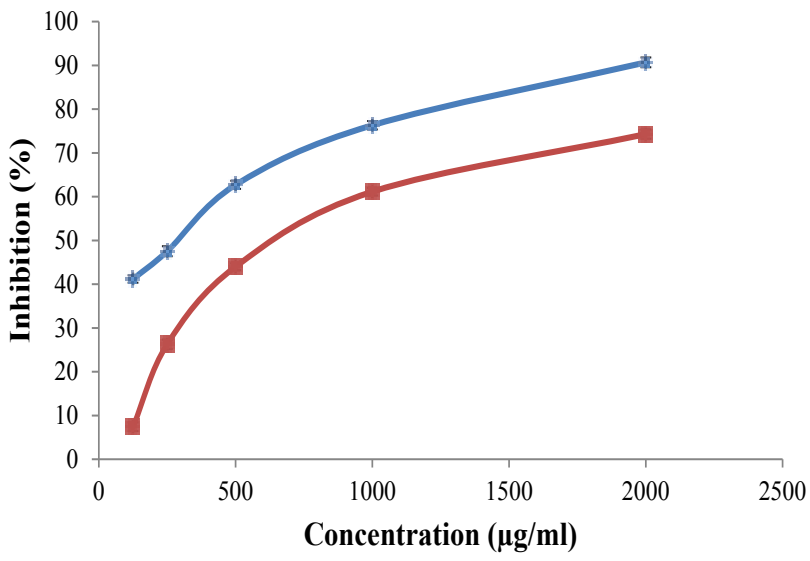

Fig. 4: Percentage inhibition curves in the superoxide radical scavenging assay

$(-\downarrow)$ ascorbic acid; (- - methanolic extract of Ophiorrhiza pectinata

of the phenolic and flavonoid compounds present in the extract. So the plant extract in its pure form can definitely exhibit significant percentage of free radical inhibition. Thus, in the present study, the methanolic plant extract exhibited significant scavenging ability against all the free radicals investigated in a dose dependent manner. The percentage inhibition of all the free radicals taken for the test increased with increasing concentration of the plant extract. The $\mathrm{IC}_{50}$ value obtained for plant extract in each assay was compared to the value obtained for the standard used in the assay and the result was good. Experiments also showed substantial amount of phenols and flavonoids that might have contributed to the antioxidant activity of the plant extract. This also justifies the usage of the plant in traditional and folklore medicines. Thus the study suggests the plant, O. pectinata, to be a potent natural antioxidant. More in vivo trials and other antioxidant mechanisms shall explore the capacity of the plant towards its usefulness in drug discovery.

\section{Acknowledgements:}

First author acknowledges the Forest Department of Kerala, India, for providing the permission for the collection of the plant specimens.

\section{Conflicts of interest:}

The authors declare that they have no conflict of interest.

\section{REFERENCES}

1. Sasidharan S, Chen Y, Saravanan D, Sundram KM, Latha LY. Extraction, isolation and characterization of bioactive compounds from plants' extracts. Afr J Tradit Complement Altern Med 2011;8(1):1-0.

2. Bajalan I, Zand M, Goodarzi M, Darabi M. Antioxidant activity and total phenolic and flavonoid content of the extract and chemical composition of the essential oil of Eremostachys laciniata collected from Zagros. Asian Pac J Trop Biomed 2017;7:144-6.

3. Al-Owaisi M, Al-Hadiwi N, Khan SA. GC-MS analysis, determination of total phenolics, flavonoid content and free radical scavenging activities of various crude extracts of Moringa peregrina (Forssk.) Fiori leaves. Asian Pac J Trop Biomed 2014;4:964-70.

4. Santos-Sánchez NF, Salas-Coronado R, Villanueva-Cañongo C, Hernández-Carlos B. Antioxidant compounds and their antioxidant mechanism. In: Antioxidants. IntechOpen; 2019. p. 1-23.

5. Bhattacharya S. Reactive oxygen species and cellular defense system. In: Free radicals in human health and disease. New Delhi: Springer; 2015. p. 17-29.

6. Al-Jaber NA, Awaad AS, Moses JE. Review on some antioxidant plants growing in Arab world. J Saudi Chem Soc 2011;15:293-307.

7. Kunwar A, Priyadarsini KI. Free radicals, oxidative stress and importance of antioxidants in human health. J Med Allied Sci 2011;1(2):53-60.

8. Adebiyi OE, Olayemi FO, Ning-Hua T, Guang-Zhi Z. In vitro antioxidant activity, total phenolic and flavonoid contents of ethanol extract of stem and leaf of Grewia carpinifolia. BeniSuef Univ J Basic Appl Sci 2017;6:10-4.

9. Saeed N, Khan MR, Shabbir M. Antioxidant activity, total phenolic and total flavonoid contents of whole plant extracts Torilis leptophylla L. BMC Complem Altern M 2012;12(1):221.

10. Shahidi F, Ambigaipalan P. Phenolics and polyphenolics in foods, beverages and spices: Antioxidant activity and health effects-A review. J Funct Foods 2015;18:820-97.

11. Mathew S, Abraham TE. In vitro antioxidant activity and scavenging effects of Cinnamomum verum leaf extract assayed by different methodologies. Food Chem Toxicol 2006;44(2):198-206.

12. Hareesh VS, Sabu M. The genus Ophiorrhiza (Rubiaceae) in Andaman and Nicobar Islands, India with a new species. Phytotaxa 2018;383:259-72.

13. Rajan R, Varghese SC, Kurup R, Gopalakrishnan R, Venkataraman R, Satheeshkumar K, et al. Search for camptothecin-yielding Ophiorrhiza species from southern Western Ghats in India: a HPTLC-densitometry study. Ind Crop Prod 2013;43:472-6.

14. Baiju EC, Asha A, Sneha J, Athira T. In vitro antioxidant and antibacterial activities of two Ophiorrhiza species. Int J Green Herb Chem 2017;7:33-8.

15. Parivuguna V, Gnanaprabhal R, Dhanabalan R, Doss A. Antimicrobial Properties and Phytochemical Constituents of Rheo discolor Hance. Ethnobotanical Leaflets 2008;12: 841-5.

16. Alabri THA, Al Musalami AHS, Hossain MA, Weli AM, AlRiyami Q. Comparative study of phytochemical screening, antioxidant and antimicrobial capacities of fresh and dry leaves crude plant extracts of Datura metel L. J King Saud Univ Sci 2014;26(3):237-43.

17. Kumar GS, Jayaveera KN, Kumar CK, Sanjay UP, Swamy BM, Kumar DV. Antimicrobial effects of Indian medicinal plants against acne-inducing bacteria. Trop J Pharm Res 2007;6(2):717-23.

18. Oueslati S, Ksouri R, Falleh H, Pichette A, Abdelly C, Legault J. Phenolic content, antioxidant, anti-inflammatory and 
anticancer activities of the edible halophyte Suaeda fruticosa Forssk. Food Chem 2012;132:943-7.

19. Chang ST, Wu JH, Wang SY, Kang PL, Yang NS, Shyur LF. Antioxidant activity of extracts from Acacia confusa bark and heartwood. J Agric Food Chem 2001;49:3420-4.

20. Kunchandy E, Rao MNA. Oxygen radical scavenging activity of curcumin. Int J Pharm 1990;58:237-40.

21. Kumaran A, Karunakaran RJ. Nitric oxide radical scavenging active components from Phyllanthus emblica L. Plant Foods Hum Nutr 2006;61:1-5.

22. Valentão P, Fernandes E, Carvalho F, Andrade PB, Seabra RM, Bastos ML (2002) Antioxidative properties of cardoon (Cynara cardunculus L.) infusion against superoxide radical, hydroxyl radical, and hypochlorous acid. J Agr Food Chem 2002;50:4989-93.

23. Mathew S, Abraham TE, Zakaria ZA. Reactivity of phenolic compounds towards free radicals under in vitro conditions. J food Sci Tech 2015;52(9):5790-5798.

24. Vazhayil BK, Sundaram RS, Patel D, Alex AR, Gomathi S, Roy $\mathrm{P}$, et al.In vitro antioxidant potential of standardized ethanol extract of Clerodendron serratum Linn. leaves. Asian J Chem 2016;28:1288-92.

25. Sultana B, Anwar F, Przybylski R. Antioxidant activity of phenolic components present in barks of Azadirachta indica,
Terminalia arjuna, Acacia nilotica, and Eugenia jambolana Lam. trees. Food Chem 2007;104:1106-14.

26. Ndhlala AR, Kasiyamhuru A, Mupure C, Chitindingu K, Benhura MA, Muchuweti M (2007) Phenolic composition of Flacourtia indica, Opuntia megacantha and Sclerocarya birrea. Food Chem 2007;103:82-7.

27. Sharma P, Jha AB, Dubey RS, Pessarakli M. Reactive oxygen species, oxidative damage, and antioxidative defense mechanism in plants under stressful conditions. J Bot 2012;2012:1-26.

28. Oleinick NL, Chiu SM, Ramakrishnan N, Xue LY. The formation, identification, and significance of DNA-protein cross-links in mammalian cells. Br J Cancer 1987;8 Suppl 1:135-40.

29. Marcocci L, Maguire JJ, Droylefaix MT, Packer L. The nitric oxide-scavenging properties of Ginkgo biloba extract EGb 761. Biochem Bioph Res Co 1994;201(2):748-55.

30. Singh D, Mishra M, Gupta M, Singh P, Gupta A, Nema R. Nitric Oxide radical scavenging assay of bioactive compounds present in methanol extract of Centella asiatica. Int J Pharm Pharm Sci Res 2012;2(3):42-4.

31. Alam MN, Bristi NJ, Rafiquzzaman M. Review on in vivo and in vitro methods evaluation of antioxidant activity. Saudi Pharm J 2013;21:143-52. 